\title{
Effect of limited and complete mating on ovaries and adrenals in bank voles, Clethrionomys glareolus
}

\author{
C. B. Andersson and T. O. Gustafsson \\ Department of Zoology, University of Lund, S-22362 Lund, Sweden
}

\begin{abstract}
Summary. Complete mating of voles induced ovulation and large and healthy CL were formed. By 4 days after mating adrenal weight was twice that in unmated animals. Limited amounts of mating (i.e. 1-3 intromissions) induced ovulation, but the resulting $C L$ were small and short-lived and no adrenal hypertrophy was seen. If limited mating was followed by mechanical genital stimulation, large CL and adrenal hypertrophy were induced. Mechanical genital stimulation alone induced ovulation (mostly small CL) in some females, but not adrenal hypertrophy. It is concluded that adrenal hypertrophy after mating in the bank vole is controlled by a neuroendocrine reflex mechanism separate from that controlling ovulation, but related to that controlling luteal function.
\end{abstract}

\section{Introduction}

Ovulation in all microtine rodents hitherto studied is induced by mating (see review by Hasler, 1975). However, studies of Microtus montanus (Davis, Gray, Zerylnick \& Dewsbury, 1974), $M$. ochrogaster (Gray, Zerylnick, Davis \& Dewsbury, 1974), M. agrestis (Milligan, 1975a), M. pennsylvanicus (Gray, Kenney \& Dewsbury, 1977) and M. californicus (Kenney, Hartung \& Dewsbury, 1979) show that the amount of mating stimulation necessary for ovulation and pregnancy varies with the species studied. In each species there seems to exist an association between male copulatory pattern and the stimulation requirements by the female for initiation of pregnancy (Gray \& Dewsbury, 1973, 1975). An unrestricted mating induces both ovulation and luteal function; if mating is limited it can still induce ovulation in $M$. agrestis and $M$. montanus, but the resulting CL are short-lived (Milligan, 1975a; Kenney \& Dewsbury, 1977). In the field vole, $M$. agrestis, at least, the development of luteal function is controlled by a neuroendocrine reflex mechanism which is distinct from that controlling ovulation. Both mechanisms are activated by mating, but by different amounts of stimulation (Milligan, 1975a). Microtus ochrogaster and $M$. californicus differ in that even limited mating results in ovulation and a functional luteal phase (Gray et al., 1974; Kenney et al., 1979).

The copulatory patterns within the genus Microtus show many similarities. They are characterized by the absence of a copulatory lock, multiple ejaculations and prolonged intromissions accompanied by pelvic thrusting. In $M$. montanus, $M$. ochrogaster and $M$. agrestis ejaculation is preceded by multiple intromissions (Dewsbury, 1973; Gray \& Dewsbury, 1973, 1975; Milligan, 1975b; Kenney et al., 1979).

A different mating pattern is found in Clethrionomys glareolus, another microtine. Bank voles show a multiple intromission/multiple ejaculation mating pattern, but intromissions are very brief (1-2 sec) without pelvic thrusting (Milligan, 1979). The relationship between this mating pattern and the induction of ovulation and luteal function has not been investigated.

In bank voles and field voles the adrenals increase in weight during pregnancy and 
pseudopregnancy (Jorne-Safriel, 1968). The change in bank voles is a 3-4-fold increase at the end of pregnancy (Andersson \& Gustafsson, 1980) and it has been shown to be induced directly by mating (Gustafsson \& Andersson, 1980).

The effect of different amounts of mating on the adrenals and ovaries of bank voles was studied in the present paper.

\section{Materials and Methods}

Laboratory bred bank voles, Clethrionomys glareolus, were used (see Gustafsson, Andersson \& Westlin, 1980). From weaning at 16 days until the beginning of the experiment, the females were kept in groups of 4-5. At the start of the experiment the animals were aged 2-4 months and were caged singly for at least 2 days and then randomly divided into 5 treatment groups: Group 1, unmated; Group 2, limited mating (1-3 intromissions); Group 3, complete mating; Group 4, mechanical genital stimulation; Group 5, limited mating followed by mechanical genital stimulation. An adult male was introduced to each female in Groups 2, 3 and 5 in the morning and the pair was either kept under constant observation until mating (Groups 2 and 5) or checked for mating every 1-2 h (Group 3 ). The male was removed after 1-3 intromissions (Groups 2 and 5), as judged by mating behaviour (Christiansen \& Døving, 1976), or left with the male for 2-4 h after initiation of mating (Group 3). If mating did not occur during the day, the male was removed and re-introduced the following day. Females that had not mated after 5 mating trials, were discarded.

In an attempt to mimic a complete mating, for some females limited mating was followed by mechanical genital stimulation (Group 5) with a plastic rod $(2 \times 20 \mathrm{~mm}$, vibrating at $50 \mathrm{~Hz})$ attached to a modified electric razor. The rod was placed in the vagina for $2 \mathrm{sec}$ at 15 -sec intervals during a $1-\mathrm{min}$ period. Ten such $1-\mathrm{min}$ stimulation periods were given at $10-\mathrm{min}$ intervals. The stimulation regimen was based on observations of the mating behaviour of bank voles (Christiansen \& Døving, 1976; Milligan, 1979).

One group of females was subjected to mechanical genital stimulation only to check whether it could induce ovulation and adrenal hypertrophy.

Animals in Groups 2-5 were killed 4 days after treatment, while the unmated controls were killed 7-14 days after grouping. At autopsy the ovaries, adrenals and uteri were weighed fresh and the ovaries were examined for CL. The ovaries were fixed in Bouin's fluid, embedded in paraffin wax, serially sectioned at $7 \mu \mathrm{m}$ and stained with Ehrlich's haematoxylin and eosin. The diameters of $C L$ were measured as the mean of two measurements at right angles through the largest section of each CL, using an eye-piece micrometer.

\section{Results}

The proportion of females ovulating and the appearance of $C L$ at autopsy after different amounts of mating is shown in Table 1. The CL were large and vascular, as characteristic of pregnancy and pseudopregnancy (functional), or small and pale (short-lived). All the CL classified as functional at autopsy proved histologically healthy, while those found to be regressing were identifiable with the ones classified as short-lived.

Only one of the unmated females had ovulated and showed regressing CL at autopsy. In most females limited mating was sufficient to induce ovulation, but the resulting CL were short-lived. All females ovulated after a complete mating and most of them had functional CL. Almost half of the females subjected to mechanical genital stimulation only had ovulated, but only one of them showed functional CL. Limited mating followed by mechanical genital stimulation resulted in ovulation and functional $\mathrm{CL}$ in a majority of the animals. 
Table 1. Body weight ( \pm s.e.m.) and the effect of different amounts of mating on ovulation and appearance of corpora lutea in female bank voles

\begin{tabular}{|c|c|c|c|c|c|c|}
\hline \multirow[b]{2}{*}{ Group } & \multirow[b]{2}{*}{ Treatment } & \multirow{2}{*}{$\begin{array}{l}\text { No. of } \\
\text { voles }\end{array}$} & \multicolumn{2}{|c|}{ No. ovulating } & \multirow{2}{*}{$\begin{array}{l}\text { No. not } \\
\text { ovulating }\end{array}$} & \multirow{2}{*}{$\begin{array}{l}\text { Body wt } \\
\text { (g) }\end{array}$} \\
\hline & & & Short-lived CL & Healthy CL & & \\
\hline 1 & Unmated & 21 & 1 & 0 & 20 & $17.4 \pm 0.5$ \\
\hline 2 & Limited mating & 18 & 15 & 0 & 3 & $\backslash 17.4 \pm 0.6$ \\
\hline 3 & Complete mating & 16 & 2 & 14 & 0 & $17 \cdot 2 \pm 0.6$ \\
\hline 4 & Mechanical stimulation & 16 & 6 & 1 & 9 & $16.8 \pm 0.7$ \\
\hline 5 & $\begin{array}{l}\text { Limited mating + mechanical } \\
\text { stimulation }\end{array}$ & 20 & 6 & 12 & 2 & $17.9 \pm 0.4$ \\
\hline
\end{tabular}

Table 2. Mean \pm s.e.m. weights of ovaries and adrenals, and diameter of CL from female bank voles after different amounts of mating (see Table 1, no. of CL measured are given in parenthesis)

\begin{tabular}{|c|c|c|c|c|c|}
\hline & $\begin{array}{c}\text { Group 1 } \\
\text { (unmated) }\end{array}$ & $\begin{array}{l}\text { Group 2 } \\
\text { (limited } \\
\text { mating) }\end{array}$ & $\begin{array}{l}\text { Group } 3 \\
\text { (complete } \\
\text { mating) }\end{array}$ & $\begin{array}{l}\text { Group 4 } \\
\text { (mechanical } \\
\text { stimulation) }\end{array}$ & $\begin{array}{c}\text { Group } 5 \\
\text { (limited mating }+ \\
\text { mechanical } \\
\text { stimulation) }\end{array}$ \\
\hline \multicolumn{6}{|l|}{ Ovarian wt (mg) } \\
\hline $\begin{array}{l}q 9 \text { not ovulating } \\
q Q \text { with short-lived } \\
\mathrm{CL}\end{array}$ & $\begin{array}{c}5.4 \pm 0.3 \\
13 \cdot 2\end{array}$ & $\begin{array}{c}8.3 \pm 1.2 \\
12.4 \pm 0.5 \dagger\end{array}$ & $11 \cdot 1 \pm \overline{1 \cdot 2 \dagger}$ & $\begin{array}{c}6.2 \pm 0.7 \\
10.3 \pm 1.9 \dagger\end{array}$ & $\begin{array}{c}8.7 \pm 0.1 \\
12 \cdot 8 \pm 0.8 \dagger\end{array}$ \\
\hline $\begin{array}{l}\bigcirc \bigcirc \text { with functional } \\
\mathrm{CL}\end{array}$ & - & - & $20 \cdot 1 \pm 1 \cdot 0^{*}$ & $24 \cdot 1$ & $21 \cdot 1 \pm 1 \cdot 5^{*}$ \\
\hline \multicolumn{6}{|l|}{ CL diameter $(\mathrm{mm})$} \\
\hline $\begin{array}{l}\text { }{ }_{\mathrm{CL}} \text { with short-lived } \\
\text { CL }\end{array}$ & $1 \cdot 21(2)$ & $1.13 \pm 0.02(42)$ & $1.00 \pm 0.05(6)$ & $1.04 \pm 0.03(14)$ & $1.05 \pm 0.06(18)$ \\
\hline$\supsetneq \wp$ with healthy $\mathbf{C L}$ & - & - & $1.45 \pm 0.03(37)^{*}$ & $1.6(1)$ & $1.41 \pm 0.04(40)^{\star}$ \\
\hline \multicolumn{6}{|l|}{ Adrenal wt (mg) } \\
\hline $\begin{array}{l}\text { } 9 \text { not ovulating } \\
\text { } \$ \text { with short-lived } \\
\text { CL }\end{array}$ & $\begin{array}{c}5.2 \pm 0.4 \\
7.0\end{array}$ & $\begin{array}{l}7.2 \pm 1.6 \\
6.9 \pm 0.5\end{array}$ & $6 \cdot 6 \pm \overline{1 \cdot 6}$ & $\begin{array}{l}5.5 \pm 0.6 \\
7.0 \pm 1.5\end{array}$ & $\begin{array}{l}5.5 \pm 1.2 \\
5.8 \pm 0.7\end{array}$ \\
\hline$q \bigcirc$ with healthy $\mathrm{CL}$ & - & - & $11 \cdot 3 \pm 1 \cdot 3^{*}$ & $11 \cdot 5$ & $15 \cdot 6 \pm 1.6^{*}$ \\
\hline
\end{tabular}

* Significantly different from females with short-lived CL, $P<0.05$ (LSD method of multiple comparisons).

$\dagger$ Significantly different from unmated females, $P<0.05$ (LSD method of multiple comparisons).

There were no differences in body weight amongst the 5 groups (Table 1), but ovarian weights did vary with the type of CL formed (Table 2). The ovaries with functional CL were heaviest but there was also a significant difference in ovarian weight between females with shortlived $C L$ and unmated females. The functional CL were significantly larger than the short-lived CL (Table 2).

A marked increase in adrenal weight occurred in females with functional CL, while adrenal weight in females with short-lived CL did not differ from that in unmated animals (Table 2).

\section{Discussion}

The present results suggest that, as in field voles (Milligan, 1975a), mating in bank voles activates two neuroendocrine reflex mechanisms which separately induce ovulation and the development of luteal function. Both mechanisms are normally activated by an unrestricted mating, while a limited mating stimulates ovulation but no functional luteal phase follows. However, the stimulation threshold for ovulation seems to be lower in bank voles than in other microtines. Ovulation is readily induced by 1-3 intromissions of 1-2 sec each, while in field 
voles, for instance, it requires an intromission of about $20 \mathrm{sec}$ to induce ovulation (Milligan, 1975a). Therefore, in bank voles, as in several other microtine species (Gray et al., 1977), there appears to be a mutual adaptation between the male mating pattern and the female stimulation requirements for the induction of ovulation and luteal function.

Mechanical genital stimulation can mimic part of the mating act in field voles (Milligan, 1975a), causing CL to become functional after an ovulatory stimulus (LH-RH or intromission). Complete mating in bank voles can also be mimicked by a few intromissions followed by mechanical genital stimulation. However, in addition to this and in contrast to previous studies of M. californicus, C. glareolus and M. agrestis (Greenwald, 1956; Clarke \& Clulow, 1973; Milligan, 1975a), the present results show that total artificial genital stimulation can induce ovulation in some bank voles. This is not unexpected when very limited mating, i.e. a few 1-2 sec intromissions, is effective in inducing ovulation. The fact that ovulation was not induced in all bank voles by mechanical stimulation is probably due to failure to mimic some factor of male stimulation during mating. It could be a lack of additional mechanical stimulation (e.g. penile spines, Zarrow \& Clark, 1968) or of other male stimuli. The importance of ovulatory stimuli other than mating has been discussed by Milligan $(1974,1975$ a) who showed that in field voles mounting without intromission or the mere presence of males could induce ovulation. Stimuli other than mating can induce ovulation in bank voles (Clarke \& Hellwing, 1977). Indeed, one of the isolated females in Group 1 of this study ovulated. The experimental females were kept in the same animal room as the breeding colony and therefore exposed to a variety of stimuli.

As expected, adrenal weight was roughly doubled by 4 days after mating compared to that of unmated animals (Andersson \& Gustafsson, 1980). This effect on the adrenals, induced by unrestricted mating (Gustafsson \& Andersson, 1980), was mimicked by limited mating followed by mechanical genital stimulation, but not by limited mating alone. These results show that, like luteal function, induction of adrenal hypertrophy requires stronger stimulation than does induction of ovulation. Irrespective of the ovulatory stimulation given, ovulation in field voles is preceded by a marked elevation of the plasma LH concentrations, but is followed by a functional luteal phase only if prolactin levels are also elevated, as they are after unrestricted mating (Milligan, 1976). However, in non-pregnant, lactating bank voles in which the prolactin levels are assumed to be fairly high, adrenal hypertrophy is not sustained (Andersson \& Gustafsson, 1980). We conclude that in bank voles a neuroendocrine reflex mechanism, separate from that controlling ovulation, but probably related to that controlling luteal function, must be stimulated to induce adrenal hypertrophy after mating. The nature of this mechanism is being investigated.

This work was supported by grants from the Swedish Natural Science Research Council and the Royal Physiographic Society of Lund. We are indebted to Miss M. Niklasson for expert technical assistance.

\section{References}

Andersson, B. \& Gustafsson, T. (1980) The adrenal cortex during and after pregnancy in the bank vole, Clethrionomys glareolus. Gen. comp. Endocr. 40, 343, Abstr.

Christiansen, E. \& Doving, K.B. (1976) Observations of the mating behavior of the bank vole, Clethrionomys glareolus. Behav. Biol. 17, 263-266.

Clarke, J.R. \& Clulow, F.W. (1973) Effect of successive matings upon bank vole, Clethrionomys glareolus, and vole, Microtus agrestis, ovaries. In The Development and Maturation of the Ovary and its Functions, pp. 160-170. Ed. H. Peters. Excerpta Medica (I.C.S. No. 267), Amsterdam.

Clarke, J.R. \& Hellwing, S. (1977) Remote control by males of ovulation in bank voles, Clethrionomys glareolus. J. Reprod. Fert. 50, 155-158.

Davis, H.N., Gray, G.D., Zerylnick, M. \& Dewsbury, D.A. (1974) Ovulation and implantation in montane voles, Microtus montanus, as a function of varying amounts of copulatory stimulation. Horm. Behav. 5, 383-388.

Dewsbury, D.A. (1973) Copulatory behavior of montane voles (Microtus montanus). Behaviour 44, 186-202.

Gray, G.D. \& Dewsbury, D.A. (1973) A quantitative description of copulatory behavior in prairie voles (Microtus ochrogaster). Brain Behav. Evol. 8, $437-452$.

Gray, G.D. \& Dewsbury, D.A. (1975) A quantitative 
description of the copulatory behavior of meadow voles (Microtus pennsylvanicus). Anim. Behav. 23, 261-267.

Gray, G.D., Zerylnick, M., Davis, H.N. \& Dewsbury, D.A. (1974) Effect of variations in male copulatory behavior on ovulation and implantation in prairie voles, Microtus ochrogaster. Horm. Behav. 5, 389396.

Gray, G.D., Kenney, A. McM. \& Dewsbury, D.A. (1977) Adaptive significance of the copulatory behavior pattern of male meadow voles (Microtus pennsylvanicus) in relation to induction of ovulation and implantation in females. J. comp. Physiol. Psychol. 91, 1308-1319.

Greenwald, G.S. (1956) The reproductive cycle of the field mouse (Microtus californicus). J. Mammal. 37, 213-222.

Gustafsson, T.O. \& Andersson, C.B. (1980) Adrenal growth during pregnancy in the bank vole, Clethrionomys glareolus: initiation by mating. Can. J. Zool. 58, 1458-1461.

Gustafsson, T., Andersson, B. \& Westlin, L. (1980) Reproduction in a laboratory colony of bank vole, Clethrionomys glareolus. Can. J. Zool. 58, 10161021.

Hasler, J.F. (1975) A review of reproduction and sexual maturation in the microtine rodents. The Biologist 57, 52-86.

Jorne-Safriel, O. (1968) Some factors affecting the adrenal juxtamedullary zone in the vole, Microtus agrestis, and bank vole, Clethrionomys glareolus. D. Phil. thesis, University of Oxford.

Kenney, A. McM. \& Dewsbury, D.A. (1977) Effect of limited mating on the corpora lutea in montane voles, Microtus montanus. J. Reprod. Fert. 49, 363-364.

Kenney, A. McM., Hartung, T.G. \& Dewsbury, D.A. (1979) Copulatory behavior and the initiation of pregnancy in California voles (Microtus californicus). Brain Behav. Evol. 16, 176-191.

Milligan, S.R. (1974) Social environment and ovulation in the vole, Microtus agrestis. J. Reprod. Fert. 41, 35-47.

Milligan, S.R. (1975a) Mating, ovulation and corpus luteum function in the vole, Microtus agrestis. $J$. Reprod. Fert. 42, 35-44.

Milligan, S.R. (1975b) The copulatory behavior of Microtus agrestis. J. Mammal. 56, 220-224.

Milligan, S.R. (1976) Correlation of plasma LH and prolactin levels with the fate of the corpus luteum in the vole, Microtus agrestis. J. Reprod. Fert. 47, 111-113.

Milligan, S.R. (1979) The copulatory pattern of the bank vole (Clethrionomys glareolus) and speculation on the role of penile spines. J. Zool., Lond. 188, 279-282.

Zarrow, M.X. \& Clark, J.H. (1968) Ovulation following vaginal stimulation in a spontaneous ovulator and its implications. J. Endocr. 40, 343-352.

Received 19 May 1981 